\title{
Serum and cerebrospinal fluid antibodies against myelin basic protein and their IgG subclass distribution in multiple sclerosis
}

\author{
ANTONIO GARCÍA-MERINO,* MATS AA PERSSON, $\dagger$ JANERNERUDH, \\ JUAN J. DÍAZ-GIL,§ TOMAS OLSSON
}

From the Departments of Neurology* and Clinical Immunology, $\dagger$ Karolinska Institutet, Huddinge University Hospital, Stockholm, Department of Neurology, $\ddagger$ University Hospital, Linköping, Sweden, and Department of Experimental Biochemistry,§ Clinica Puerta de Hierro, Madrid, Spain

SUMMARY IgG class antibodies reactive with myelin basic protein (MBP) were determined by enzyme-linked immunosorbent assay (ELISA) in serum and cerebrospinal fluid (CSF) of 37 patients with multiple sclerosis and a control group of 32 patients with tension headache or psychoneurosis. Using standardised amounts of IgG from CSF and serum in ELISA, significantly higher mean antibody levels were found in CSF as well as in serum from the patients with multiple sclerosis. Ten $(27 \%)$ of the multiple sclerosis CSF samples and $15(41 \%)$ of the multiple sclerosis sera revealed anti MBP antibody levels exceeding 2 SD of the control group. Seven patients (19\%) showed exclusive or higher levels of anti MBP antibodies in CSF, suggesting synthesis within the central nervous system. Analysis by ELISA for IgG subclasses of anti MBP antibodies revealed that they were restricted to IgG 1 in four patients and IgG 3 in one.

Immunoglobulin aberrations especially of the cerebrospinal fluid (CSF) are important characteristics of multiple sclerosis. ${ }^{12}$ The biological significance of the CSF IgG and its antigenic specificity are largely unknown.

Since the identification of myelin basic protein (MBP) as the antigen causing experimental allergic encephalomyelitis (EAE), ${ }^{3}$ much interest has been devoted to this protein, mainly regarding its possible pathogenetic role as a target for the immune attack in multiple sclerosis. With regard to antibodies directed against MBP, results have been conflicting. While some authors reported low levels of anti MBP antibodies in multiple sclerosis patients, ${ }^{4}$ other authors report negative results. ${ }^{5}$ The main reasons for these discrepancies include differences in methodology and selection of patients.

Address for reprint requests: $\mathrm{Dr}$ Antonio García-Merino, Department of Neurology, Clínica Puerta de Hierro, San Martín de Porres 4, 28035 Madrid, Spain.

Received 2 July 1985 and in revised form 18 November 1985.

Accepted 23 November 1985
Most previous studies of human anti MBP antibodies have employed various radioimmunoassays and protein blotting techniques. Enzyme-linked immunosorbent assay (ELISA) may be better than radioimmunoassays, because it is more convenient and simple, and involves more stable reagents. ${ }^{6}$ The present study was undertaken to analyse whether ELISA could delineate multiple sclerosis patients with antibodies directed against MBP in their sera and CSF. A further purpose was to select positive samples for definition of IgG subclass distribution of the anti MBP antibodies, by a second ELISA. Such subclass distribution data would be important for further understanding of the biological role and production of the anti MBP antibodies.

\section{Material and methods}

Patients. Forty seven paired samples of CSF and serum taken simultaneously from 37 patients with definite (31) or probable (6) multiple sclerosis, diagnosed according to the criteria given by Rose et al, ${ }^{7}$ were analysed. A control group of paired serum and CSF samples from 32 patients with tension headache or psychoneurosis was included. The two groups had a similar age distribution. 
Routine CSF and serum studies. $15 \mathrm{ml}$ of CSF was obtained by lumbar puncture, examined for cell quantities by phase contrast microscopy and centrifuged at $200 \mathrm{~g}$ for 10 minutes. The erythrocyte count in CSF did not exceed $100 \times 10^{6}$ cells/1. Determinations of albumin, IgG and IgA were carried out by immunoprecipitation nephelometry on unconcentrated CSF and on serum obtained in parallel. The CSF IgG index was calculated. ${ }^{8}$ The upper limit in our laboratory is 0.7 . As indicator of the blood-brain barrier status, the CSF albumin/serum albumin ratio was determined. Oligoclonal IgG bands were demonstrated on unconcentrated CSF samples and diluted sera, according to described methods. ${ }^{9}$

Myelin basic protein. Normal appearing white matter was obtained within 4 hours after death from a patient who died of non-neurological disease. MBP was purified by ionexchange chromatography ${ }^{10}$ and gel filtration of G-50 Superfine (Pharmacia Fine Chemicals, Uppsala, Sweden). The preparation of MBP was found to be pure on SDS polyacrylamide gel electrophoresis.

ELISA for detection of antibodies against myelin basic protein. Methods for detection of anti MBP antibodies in experimental animals ${ }^{11-13}$ were modified. To ELISA plates (Dynatech M 129B; Dynatech, Zug, Switzerland) coated over night with $\mathrm{MBP}, 5 \mu \mathrm{g} / \mathrm{ml}$ in $0.01 \mathrm{M}$ phosphate buffer, $\mathrm{pH} 6.0$, and saturated with bovine serum albumin (BSA, product No. A-4503, Sigma Chemical Co, St. Louis, MO, USA) $10 \mathrm{mg} / \mathrm{ml}$ and histones (Type II-AS, Sigma) $1 \mathrm{mg} / \mathrm{ml}$, were added in sequence $200 \mu \mathrm{l} /$ well aliquots of: (1) samples, in duplicate, adjusted to constant IgG concentrations of 15 $\mu \mathrm{g} / \mathrm{ml}$, and incubated $2 \mathrm{~h}$ at $37^{\circ} \mathrm{C}$; (2) rabbit anti-human IgG, gamma-chains specific (Dakopatts, Copenhagen, Denmark), diluted 1:4000 and kept over night at room temperature; (3) alkaline phosphatase conjugated goat anti-rabbit IgG (Miles-Yeda Ltd, Israel), diluted 1:2500, and incubated for $4 \mathrm{~h}$ at room temperature. Samples and

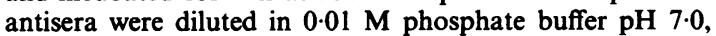
containing $1 \%$ BSA, $1.2 \% \mathrm{NaCl}, 0.5 \%$ Tween 80 , and $0 \cdot 1 \%$ histones. After addition of substrate (disodium p-nitro-phenylphosphate from Sigma, $1 \mathrm{mg} / \mathrm{ml}$ in $10 \%$ diethanolamine buffer, $\mathrm{pH} 9.8$ ) the reaction was read after 90 minutes at $405 \mathrm{~nm}$ in a Titertek Multiscan (Eflab Oy, Helsinki, Finland). Background value obtained by adding only diluting buffer instead of sample to some coated wells, was calculated in each plate and subtracted from all the readings. To avoid variations in results, these were expressed as arbitrary units related to a multiple sclerosis CSF sample, which was found to have higher optical density values than the mean of control CSF samples in preliminary experiments, and run in each plate.

ELISA for determination of anti MBP IgG antibody subclasses. Monoclonal antibodies to IgG subclasses ${ }^{14}$ were purchased from Seward Laboratories, Bedford, Buckinghamshire, UK. The following monoclonals were used: anti-IgG1 BAm 15, anti IgG2 BAM 10, anti-IgG3 BAM 8, and anti-IgG4 BAM 16. They were purified from ascitic fluid as described. ${ }^{15}$ Rabbit anti-mouse IgG antiserum was supplied by Dakopatts A/S (product No. Z 109), and absorbed to human proteins before use. Alkaline phosphatase conjugated goat anti-rabbit IgG was purchased from Sigma (product No. F 8025). The method for IgG subclass determination has been described elsewhere. ${ }^{15}$

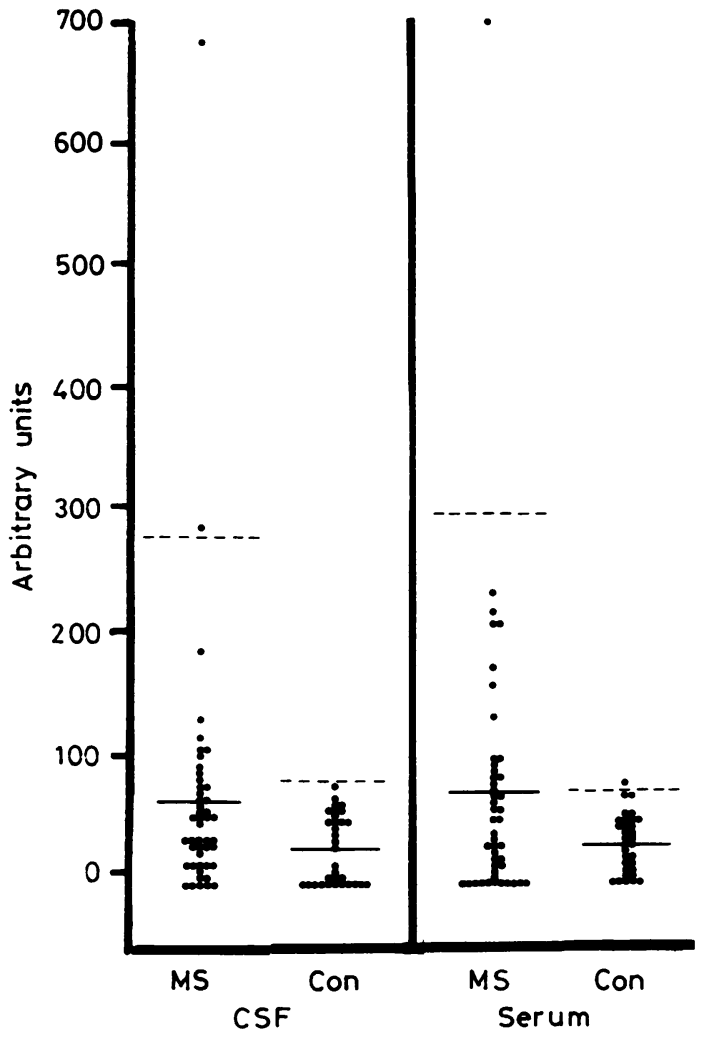

Fig Arbitrary units in ELISA for IgG anti MBP antibodies in cerebrospinal fluid (CSF) and serum of multiple sclerosis (MS) and control (CON) patients. Full lines indicate mean values, broken lines indicate $2 S D$ in each group.

\section{Results}

Routine studies of CSF and serum revealed that all except three of the 37 patients with multiple sclerosis had increased CSF IgG index, and all but one had oligoclonal IgG bands. All 32 patients in the control group were negative in these respects.

ELISA for detection of antibodies reactive with MBP revealed a significantly higher ( $p<0.01$; MannWhitney's U contrast test) mean value in the CSF of multiple sclerosis patients compared with controls (Fig. 1). Ten of the 37 multiple sclerosis patients (27\%) had values in CSF exceeding 2 SD of the controls. In sera, the mean value of anti MBP antibodies was also higher for multiple sclerosis patients than controls ( $p<0.01$ ) (fig). Values in 15 of 37 multiple sclerosis sera $(40 \%)$ exceeded 2 SD of the control sera.

A comparison of CSF and serum values of the same individuals exceeding 2 SD of controls, revealed eight patients having anti MBP antibodies both in 
serum and CSF, five of them with higher values in CSF than serum (arbitrary units in CSF/arbitrary units in serum $>1.0$ ), and three with higher values in serum than in CSF (arbitrary units in CSF/arbitrary units in serum $<1 \cdot 0$ ). Two patients had anti MBP antibodies in CSF only, and seven patients had such antibodies in serum only. This means that we obtained evidence for production of anti MBP antibodies within the CNS in seven (19\%) of our multiple sclerosis patients.

Ten patients with multiple sclerosis in whom anti MBP antibody values in CSF and/or serum exceeded 2 SD of controls were selected for IgG subclass analysis. In seven of them both CSF and serum were studied, in only only CSF, and in the remaining two only serum. Using optical densities, read at $405 \mathrm{~nm}$ over $0 \cdot 100$ after background subtraction, to delineate subclass specific antibodies ${ }^{15}$ this ELISA revealed the IgG subclass distribution of the anti MBP antibodies in five patients. Three of them had increased anti MBP levels in both serum and CSF, one had increased levels in serum only, and one in CSF only. In four of the patients, the antibodies were of the IgG 1 subclass only, in the remaining one of the IgG 3 only. In this last mentioned patient the subclass distribution was identical in three samples taken 6 months apart (table).

\section{Discussion}

The present study corroborates previous findings of anti MBP antibodies of IgG class in CSF and serum of a substantial number of multiple sclerosis patients, compared with controls without evidence of inflammatory disease of the CNS. Nevertheless there is a large proportion of patients with multiple sclerosis who in various analyses do not show detectable amounts of anti MBP antibodies. From these data the biological significance of anti MBP antibodies cannot be evaluated; whether they are a part of a primary, pathogenetically important immune response or represent secondary responses of unknown significance remains unanswered.

Firstly, MBP is a strongly positively charged molecule and by this it is very prone to bind IgG nonspecifically. This makes it difficult to estimate amounts of anti MBP specific antibodies. In the present study some of these difficulties have been overcome by applying constant amounts of serum IgG and CSF IgG, and by the use of histones which are known to inhibit non-specific binding when applied at high concentrations. ${ }^{1116}$ These difficulties have also the implication that lower amounts of antibodies may be "hidden" in a large non-specific background, and the proportion of patients having anti MBP antibodies may well be higher. Secondly, antibodies against MBP or other structural nervous tissue antigens may be produced in vivo but absorbed to the target and, therefore, not be detected as free immunoglobulins. In fact, we have recently demonstrated in animals with chronic relapsing encephalomyelitis that production of antibodies against myelin or MBP is easily detected in vitro culture supernatants of CNS lymphocytes ${ }^{17}$ but not in brain extracts. Thirdly, whether anti MBP antibodies belonging to other immunoglobulin classes may appear in multiple sclerosis remains to be elucidated.

The site of production of anti MBP antibodies is controversial; intra- or extrathecally or both. It has been claimed that antibodies appeared in CSF only after passive transudation from serum. ${ }^{18}$ In the present study parallel estimations of anti MBP antibodies was made both in serum and CSF samples. Higher anti MBP antibody values in CSF compared with serum would indicate an intrathecal production site and was found in seven of our 37 patients (19\%). When values were similar in CSF and serum or higher in serum, the site of production may not be accurately

Table IgG subclass distribution of anti MBP antibodies in CSF and serum from five patients with multiple sclerosis

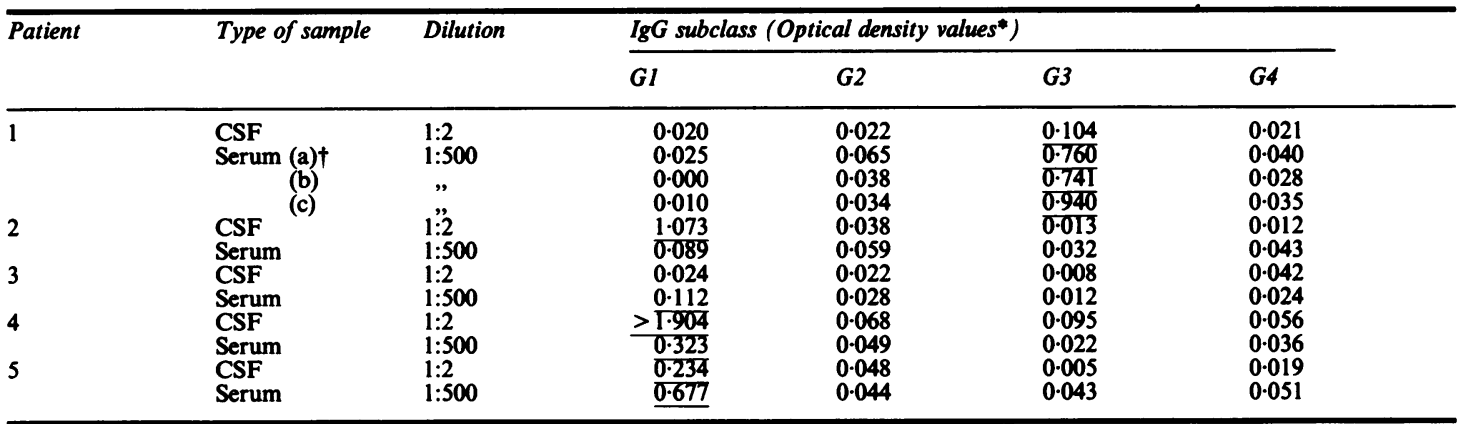

-Optical density at nm values, read at 90 min. Background subtracted.

+CSF and serum (a) drawn at the same occasion; serum (b) six months before, and serum (c) six months afterwards.

Arbitrarily, samples with $O D$ values $0 \cdot 100$ or higher are regarded as positive and underlined. 
determined, mainly due to putative absorption effects, as discussed above.

Another new observation in the present study is the IgG subclass distribution of the anti MBP antibodies. A lower sensitivity of the subclass assay might explain that fewer samples were positive in this assay compared to the ordinary anti MBP assay. IgG restricted with regard to subclass distribution has been shown to appear in responses to certain antigens and mitogens. ${ }^{19}$ In general, specific antibodies to protein antigens belong to IgG 1 and IgG $4 .^{2021}$ Mostly, antibodies belonging to two subclasses appear simultaneously. This is also true for antimeasles antibodies in multiple sclerosis CSF, since they appear both as IgG 1 and IgG 4 simultaneously in the same individual. ${ }^{22}$ The presently observed restriction to only one IgG subclass (IgG 1 or IgG 3 ) of the anti MBP antibodies is thus divergent from the usual pattern of response. This restriction suggests a monoclonal or at least oligoclonal origin of these antibodies. One of our patients with multiple sclerosis displayed in fact IgG 3 anti MBP antibodies at three occasions over a one year period, but no antibodies belonging to any other subclass, which might suggest that no subclass switch occurred during our observation period, a phenomenon suggested to take place after repeated immunisation. ${ }^{23}$ Since both IgG 1 and IgG 3 subclasses are cytophilic for monocytes and macrophages in man, ${ }^{24}$ the presently observed anti MBP antibodies could have a role in antibodydependent macrophage-mediated myelin breakdown, in particular in view of the demonstration of capping of surface IgG on macrophages contacting myelinated nerve fibers in active multiple sclerosis lesions. ${ }^{25}$

The occurrence of anti MBP antibodies of the IgG 3 subclass has also practical implications: since staphylococcal protein A does not bind significantly IgG 3, assays for anti MBP antibodies should not involve enzyme or ${ }^{125} \mathrm{I}$-labelled protein A.

In conclusion, the present study demonstrates that it is feasible to monitor anti MBP antibodies in CSF and serum using an ELISA and to further characterise IgG subclasses of these antibodies. The anti MBP antibodies found among our 37 patients with multiple sclerosis were either of IgG 1 or IgG 3 subclass, which may be important for the understanding of the biological significance of these antibodies.

This study was supported by grants from the Spanish "Fondo de Investigaciones Sanitarias de la Seguridad Social", the Swedish Medical Research Council (project No. 3381), Tore Nilson's Fund for Medical Research, Östergotlands Läns Landsting, the Swedish Society for Medical Sciences and the Foundation in memory of Sigurd and Elsa Golje.
We thank Professor Hans Link, Department of Neurology, Karolinska Institutet, Huddinge University Hospital, Stockholm, for valuable critical advice, and Dr Isabel Millán for her help in statistical calculations.

\section{References}

${ }^{1}$ Link H. Characteristics of the immune response within the CNS in neurological disorders. Acta Neurol Scand 1978,57, suppl 67:177-90.

${ }^{2}$ Trotter JL, Brooks BR. Pathophysiology of cerebrospinal fluid immunoglobulins. In JH Wood ed. Neurobiology of Cerebrospinal Fluid, New York: Plenum Press, 1980:465-86.

${ }^{3}$ Kies MW, Alvord EC Jr. Allergic Encephalomyelitis, Springfield, Charles C Thomas, 1959.

${ }^{4}$ Panitch HS, Hooper CJ, Johnson KP. CSF antibody to myelin basic protein. Measurement in patients with multiple sclerosis and subacute sclerosing panencephalitis. Arch Neurol 1980;37:206-9.

${ }^{5}$ Chou C-HJ, Tourtellotte WW, Kibler RF. Failure to detect antibodies to myelin basic protein or peptic fragments of myelin basic protein in CSF of patients with MS. Neurology (Cleveland) 1983;33:24-8.

${ }^{6}$ Engvall E, Perlmann P. Enzyme-linked immunosorbent assay (ELISA). Quantitative assay of immunoglobulin G. Immunochemistry 1971;8:871-4.

${ }^{7}$ Rose AS, Ellison GW, Myers LW, Tourtellotte WW. Criteria for the clinical diagnosis of multiple sclerosis. $\mathrm{Neu}$ rology (Minneap) 1976;26 suppl:20-2.

${ }^{8}$ Tibbling G, Link H, Öhman S. Principles of albumin and IgG analysis in neurological disorders. I. Establishment of reference values. Scand $J$ Clin Lab Invest 1977;37:385-90.

${ }^{9}$ Olsson T, Kostulas V, Link H. Improved detection of oligoclonal IgG in cerebrospinal fluid by isoelectric focusing in agarose, double-antibody peroxidase labeling, and avidin-biotin amplification. Clin Chem 1984;30:1246-9.

${ }^{10}$ Chou FC-H, Chou C-HJ, Shapira R, Kibler RF. Basis of microheterogeneity of myelin basic protein. J Biol Chem 1976;251:2671-9.

${ }^{11}$ Groome NP. Enzyme-linked immunosorbent assays for myelin basic protein and antibodies to myelin basic protein. $J$ Neurochem 1980;35:1409-17.

${ }^{12}$ Olsson T, Henriksson A, Link H, Kristensson K. IgM and IgG responses during chronic relapsing experimental allergic encephalomyelitis (r-EAE). J Neuroimmunol 1984;6:265-81.

${ }^{13}$ Spatz L, Whitman L, Messito MJ, Nilaver G, Ginsberg G, Latov N. Measurement of myelin basic protein and of anti-basic protein antibodies by ELISA utilizing biotinylated antibodies. Immunol Commun 1983;12:31-7.

${ }^{14}$ Lowe J, Bird P, Hardie D, Jefferis R, Ling NR. Monoclonal antibodies (McAbs) to determinants of human gamma chains: properties of antibodies showing subclass restriction or subclass specificity. Immunology 1982;47:329-36.

${ }^{15}$ Persson MAA, Hammarström L, Smith CIE. Enzyme- 
linked immunosorbent assay for subclass distribution of human $\operatorname{IgG}$ and $\operatorname{IgA}$ antigen-specific antibodies. $J$ Immunol Methods 1985;78:109-21.

${ }^{16}$ Sindic CJM, Cambiaso CL, Masson PL, Laterre EC. The binding of myelin basic protein to the Fc region of aggregated IgG and to immune complexes. Clin Exp Immunol 1980;41:1-7.

${ }^{17}$ Olsson T, Henriksson A, Link H, Kristensson K. Humoral immune response in chronic relapsing allergic encephalomyelitis (r-EAE) in guinea pigs. In: Experimental Allergic Encephalomyelitis. A Useful Model for Multiple Sclerosis. Alan R Liss Inc, New York 1984;179-86.

${ }^{18}$ Gutstein HS, Cohen SR: Spinal fluid differences in experimental allergic encephalomyelitis and multiple sclerosis. Science 1978;199:301-2.

${ }^{19}$ Shakib F, Stanworth DR. Human IgG subclasses in health and disease, part II. La Ricerca Clin Lab 1980;10:561-80.

${ }^{20}$ Hammarström L, Granström M, Oxelius V, Persson MAA, Smith CIE. IgG subclass distribution of anti- bodies against $\mathbf{S}$ aureus teichoic acid and alpha-toxin in normal and immunodeficient donors. Clin Exp Immunol 1984;55:593-601.

${ }^{21}$ Linde A, Hammarström L, Persson MAA, Smith CIE, Sundqvist V-A, Wahren B. Virus-specific antibody activity of different subclasses of immunoglobulins $G$ and $A$ in cytomegalovirus infections. Infect Immun 1983;42:237-44.

${ }^{22}$ Persson MAA, Laurenzi MA: IgG subclass pattern of specific antibodies in serum and CSF in patients with MS and SSPE. Submitted.

${ }^{23}$ Aalberse RC, van der Gaag R, van Leeuwen J. Serologic aspects of IgG 4 antibodies. I. Prolonged immunization results in an IgG 4-restricted response. J Immunol 1983;130:722-6.

${ }^{24}$ Lawrence DA, Weigle WO, Spielgelberg HL. Immunoglobulins cytophilic for human lymphocytes, monocytes and neutrophils. J Clin Invest 1975;55:368-76.

${ }^{25}$ Prineas JW, Graham JS. Multiple sclerosis: capping of surface immunoglobulin $\mathrm{G}$ on macrophages engaged in myelin breakdown. Ann Neurol 1981;10:149-58. 